\title{
ApoE isoforms differentially regulates cleavage and secretion of BDNF
}

\author{
Abhik Sen ${ }^{*}$ (D), Thomas J. Nelson and Daniel L. Alkon
}

\begin{abstract}
Apolipoprotein E4 (ApoE4) is a major genetic risk factor for sporadic or late onset Alzheimer's disease (AD). Brain-derived neurotrophic factor (BDNF) is decreased by 3 to 4 -fold in the brains of AD patients at autopsy. ApoE4 mice also have reduced BDNF levels. However, there have been no reports relating the different ApoE isoforms or AD to differential regulation of BDNF. Here we report that in the hippocampal regions of AD patients both prepro-BDNF and pro-BDNF expression showed a 40 and $60 \%$ decrease respectively compared to that expression in the hippocampi of age-matched control patients. We further report that ApoE isoforms differentially regulate maturation and secretion of BDNF from primary human astrocytes. After $24 \mathrm{~h}$, ApoE3 treated astrocytes secreted 1.75- fold higher pro-BDNF than ApoE2-treated astrocytes, and ApoE2-treated astrocytes secreted 3-fold more mature-BDNF ( $m$-BDNF) than ApoE3-treated astrocytes. In contrast, ApoE4-treated cells secreted negligible amounts of m-BDNF or pro-BDNF. ApoE2 increased the level of intracellular pre-pro BDNF by $19.04 \pm 6.68 \%$, while ApoE4 reduced the pre-pro BDNF by $21.61 \pm 5.9 \%$ compared to untreated cells. Similar results were also seen in ApoE2, ApoE3 or ApoE4 treated cells at $4 \mathrm{~h}$. Together, these results indicate that an ApoE2 or ApoE3 mediated positive regulation of BDNF may be protective while ApoE4 related defects in BDNF processing could lead to AD pathophysiology. These interactions of the ApoE isoforms with BDNF may help explain the increased risk of AD associated with the ApoE4 isoform.
\end{abstract}

Keywords: Alzheimer's disease (AD), Apolipoprotein E (ApoE), Brain-derived neurotrophic factor (BDNF)

\section{Introduction}

The discovery of the apolipoprotein E (ApoE) 4 allele as a major risk factor for sporadic and late-onset familial $\mathrm{AD}$ has brought attention to the possible role of ApoE in neurodegenerative conditions. The human ApoE gene exists as three polymorphic alleles- $-\varepsilon 2, \varepsilon 3$ and $\varepsilon 4-$ which have a worldwide frequency of $8.4,77.9$, and $13.7 \%$, respectively [1]. The presence of the ApoE4 allele is associated with increased risk of cerebral amyloid angiopathy and age-related cognitive decline during normal aging [2]. The ApoE4 allele is also a risk factor for other neurodegenerative conditions, such as Parkinson's and multiple sclerosis, and is associated with worse outcomes after ischemic or traumatic brain injury [3].

In the CNS, the ApoE protein is mainly produced by astrocytes and transports cholesterol to neurons via the lowdensity lipoprotein receptor (LDLR) family. ApoE is an essential component for axonal growth and synaptic

* Correspondence: asen@hsc.wvu.edu

Blanchette Rockefeller Neurosciences Institute, 8 Medical Center Drive, Morgantown, WV 26505, USA formation and remodeling-events that are crucial for learning, memory formation, and neuronal repair. ApoE also regulates hippocampal neurogenesis by maintaining the neural progenitor cell pool in the adult dentate gyrus region of the hippocampus [4]. In AD and healthy aged controls, APOE $\varepsilon 4$ gene dosage correlates inversely with dendritic spine density in the hippocampus [5]. Reduced synaptic transmission was observed in 1monthold ApoE4transgenic mice compared with ApoE3transgenic mice, suggesting that ApoE4 may also contribute to functional deficits early in development, which may account for alterations in neuronal circuitry that result in cognitive disorders later in life [6]. ApoE4 not only increases $A \beta$ deposition but also affects synaptic repair, plasticity and neural development $[2,7]$. We have also shown that ApoE3 acts through $\mathrm{PKC \varepsilon}$ to protect primary neurons against $A \beta$-induced cell death and induce synaptogenesis, whereas ApoE4 does not [8]. Furthermore, ApoE4 epigenetically suppresses BDNF mRNA expression by inducing nuclear translocation of histone deacetylases 4 and 6 (HDACs) in human neurons [9]. 
Brain-derived neurotrophic factor (BDNF) is a critical factor in synaptic repair and plasticity. Considerable evidence suggests that a decrease in BDNF is associated with AD. BDNF expression is greatly decreased in the hippocampus and temporal and frontal cortex of $\mathrm{AD}$ patients [10]. BDNF mRNA is decreased in parietal cortex and hippocampus by 3 to 4-fold in $\mathrm{AD}$ autopsy samples [11]; both precursor and mature BDNF are dramatically decreased in preclinical stages of $\mathrm{AD}$, and correlate with behavioral scores [12]. Although evidence for BDNF polymorphisms in $\mathrm{AD}$ is still inconclusive, synaptic loss is the single most important correlate of $\mathrm{AD}$. BDNF protein is synthesized as pre-proBDNF and cleaved into a proBDNF protein. ProBDNF is either cleaved intracellularly or extracellularly to mature BDNF (mBDNF). Pro-BDNF and mBDNF function differently although it has not been previously known whether ApoE isoforms differentially regulate the cleavage of pro-BDNF.

Astrocytes are a well characterized source for biologically active molecules including BDNF, both in culture and in vivo. Astrocytes are known to produce BDNF in vivo following injury [13]. In culture, they increase BDNF synthesis and release in response to glutamate metabotropic stimulation. Numerous glutamate signaling proteins are downregulated in ApoE4 mice [14]. Since ApoE in the brain is mainly produced by the astrocytes we investigated whether the ApoE isoforms have an effect on the maturation and secretion of BDNF from astrocytes.

\section{Methods}

\section{Materials}

Cell culture media were obtained from Sciencell, CA, USA. Recombinant human ApoE2 (rh-ApoE2), ApoE3 (rh-ApoE3), ApoE4 (rh-ApoE3), and other reagents were purchased from Sigma-Aldrich (St. Louis, MO, USA). Primary antibodies against BDNF and $\beta$-actin were obtained from Santa Cruz Biotechnology, Inc. (Santa Cruz, CA, USA); all secondary antibodies were purchased from Jackson ImmunoResearch Laboratories, Inc. (Bar Harbor, ME, USA).

\section{Culture of primary human astrocytes}

Human primary astrocytes (ScienCell Research Laboratories, Carlsbad, CA, USA) were plated on poly-L-lysine coated plates and were maintained in astrocyte medium (ScienCell Research Laboratories, Carlsbad, CA, USA) supplemented with the astrocyte growth supplement (AGS, ScienCell Research Laboratories, Carlsbad, CA, USA) and 2\% fetal bovine serum (FBS). For maintenance of astrocytes, the media was changed every 3 days. Before treatment of the cells, the media was replaced with serum and growth factor free DMEM/F12 media (Invitrogen, Carlsbad, CA). Cells were treated with cholesterol, or ApoE2/ApoE3/
ApoE4 + cholesterol for 4 and $24 \mathrm{~h}$. ApoE (20 nM) and cholesterol $(100 \mu \mathrm{M})$ were added separately to the cultures. Cholesterol was dissolved in ethanol.

\section{Collection of cell secreted media}

Media from the treated cells was collected using a pipette. The collected media was concentrated 10-fold using a 3-kDa molecular-cut filter (Amicon Ultra-4, Millipore, Tullagreen, Ireland).

\section{Human brain tissue}

Fresh frozen human brain tissue was obtained from the Harvard Brain Tissue Resource Center, McLean Hospital, Boston, MA which is the part of NIH NeuroBioBank (IRB: Partners Human Research Committee; Title: Brain Tissue Repository for Research on Neurological and Psychiatric Disorders; IRB No: 2015P002028) (Table 1). Approval for the study was obtained from tissue access committee of NIH NeuroBioBank (https://neurobiobank.nih.gov/ documents/). Informed consent was obtained from all patients or legal representatives. The pathological diagnosis of $\mathrm{AD}$ was conducted according to the Consortium to Establish a Registry for Alzheimer's disease (CERAD). The study was carried out in accordance with the Code of Ethics of the World Medical Association (Declaration of Helsinki) for experiments involving humans (http://www.share-project.org/fileadmin/pdf_ documentation/Declaration_of_Helsinki.pdf).

\section{Cell and tissue protein preparation}

Cells and tissue were harvested in homogenizing buffer, containing $10 \mathrm{mM}$ Tris- $\mathrm{Cl}$ (pH 7.4), $1 \mathrm{mM}$ PMSF (phenylmethylsulfonyl fluoride), $1 \mathrm{mM}$ EGTA, $1 \mathrm{mM}$ EDTA, $50 \mathrm{mM} \mathrm{NaF}, 20 \mu \mathrm{M}$ leupeptin and 1\% NP-40 and were lysed by sonication. Protein concentration was measured

Table 1 Patient ID, Braak stage and age of human brain tissue

\begin{tabular}{lllcl}
\hline Patient ID & Gender & Age & Average age \pm SD & Autopsy diagnosis \\
\hline AN02930 & M & 80 & $77.5 \pm 12.34$ & AD Braak 3 \\
AN14554 & F & 61 & & AD Braak 6 \\
AN17726 & M & 72 & AD Braak 2 \\
AN06468 & M & 98 & AD Braak 4 \\
AN16195 & F & 73 & & AD Braak 5 \\
AN02773 & F & 81 & & AD Braak 5 \\
AN00704 & F & 82 & $77.4 \pm 5.86$ & Control \\
AN00316 & F & 75 & & Control \\
AN17896 & M & 69 & & Control \\
AN12667 & M & 86 & & Control \\
AN08396 & M & 76 & Control \\
AN15515 & M & 73 & & Control \\
AN10329 & F & 81 & & Control \\
\hline
\end{tabular}


using the Coomassie Plus (Bradford) Protein Assay kit (Pierce, Rockford, IL, USA).

\section{Immunoblot}

Following quantification, $40 \mu \mathrm{g}$ of protein from each sample was subjected to SDS-PAGE analysis in 4-20\% gradient Tris-Glycine gel (Invitrogen, Carlsbad, CA, USA). The separated protein was then transferred to a nitrocellulose membrane. The membrane was blocked with BSA at room temperature for $15 \mathrm{~min}$ and was incubated with primary antibody overnight at $4{ }^{\circ} \mathrm{C}$. After incubation, it was washed $3 \times$ with TBS-T (Tris-buffered saline-Tween 20) and further incubated with alkaline phosphatase conjugated secondary antibody (Jackson Immunoresearch Laboratories) at 1:10,000 dilution for $45 \mathrm{~min}$. The membrane was finally washed $3 \times$ with TBS-T and developed using the 1-step NBT-BCIP substrate (Pierce, Rockford, IL, USA). The blot was imaged in the ImageQuant RT-ECL (GE Life Sciences, Piscataway, NJ, USA) and densitometric quantification was performed using IMAL software. For quantifying expression of a protein, densitometric values for the protein of interest were normalized against $\beta$-actin (loading control).

\section{Statistical analysis}

All experiments were performed at least three times. Data are represented as mean \pm SEM. Data containing more than two groups was analyzed using one-way ANOVA with post-hoc Newman-Keuls multiple comparison test. Data with two groups were tested for significance with paired two-tailed $t$ test comparisons using GraphPad Prism 6.1 software (La Jolla, CA, USA). $P$ values $<0.05$ were considered statistically significant.

\section{Results}

BDNF levels are lower in autopsy-confirmed human AD hippocampus

To determine if BDNF levels are affected in AD brain, we measured the BDNF levels from autopsy-confirmed human $\mathrm{AD}$ hippocampus (Average age $=77.5 \pm 12.34$ $(\mathrm{SD}) ; n=6)$ and aged matched control (AC) human hippocampus (Average age $=77.4 \pm 5.86(\mathrm{SD}) ; n=7$ ) using immunoblot. In $\mathrm{AD}$ hippocampus both the preproBDNF and pro-BDNF levels were significantly lower than AC hippocampus (Fig. 1b, d). No m-BDNF was detected in these samples. Both prepro-BDNF and pro-BDNF levels showed a negative correlation (not significant) with the Braak stage among AD cases (Fig. 1c, e).

\section{ApoE isoforms differentially regulate the secretion of mature BDNF from human astrocytes}

To evaluate the effect of ApoE2, ApoE3 and ApoE4, primary human hippocampal astrocytes were grown in serum free media and treated with cholesterol $(100 \mu \mathrm{M})$,

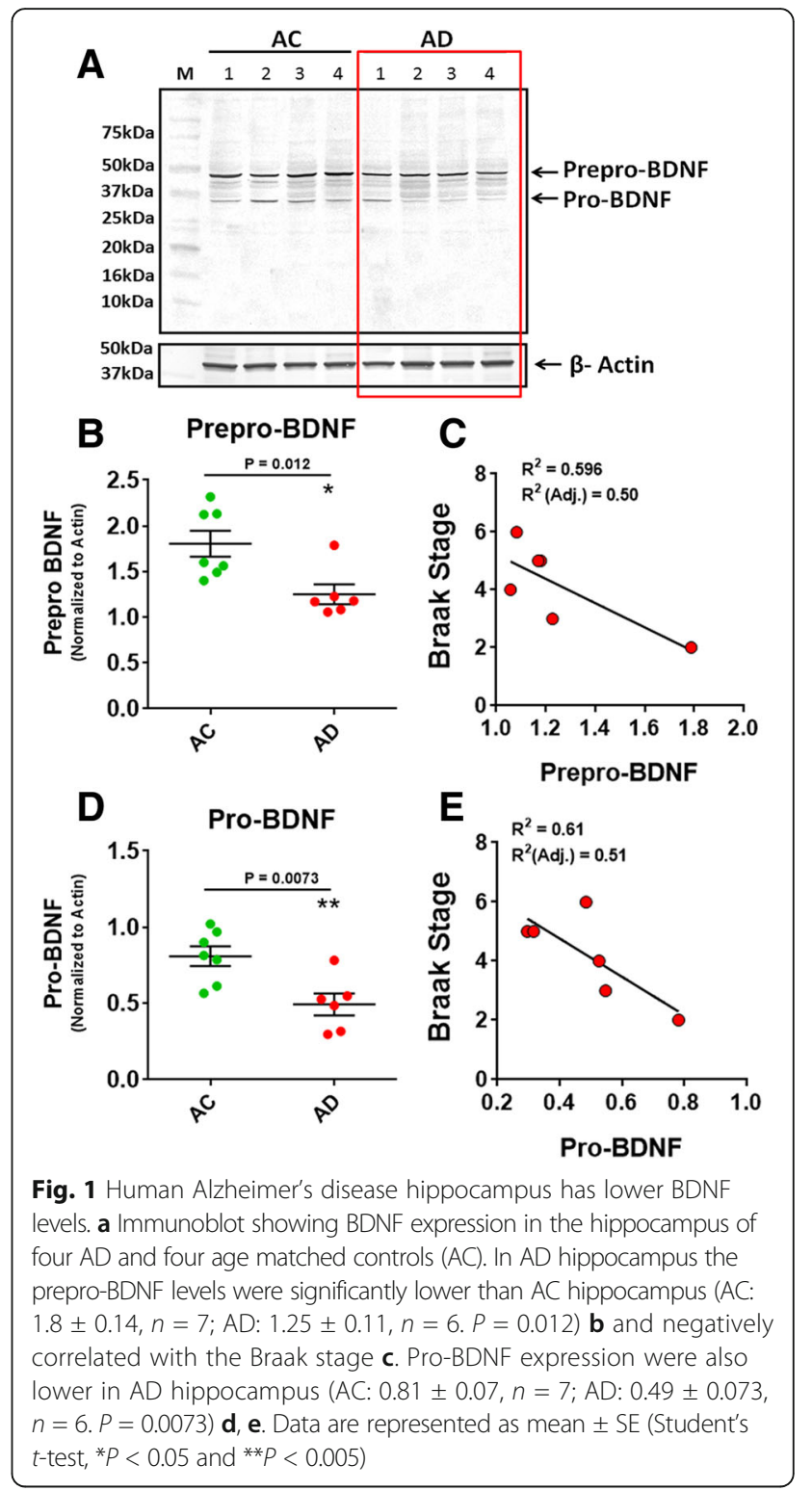

ApoE2 $(20 \mathrm{nM})+$ cholesterol, ApoE3 $(20 \mathrm{nM})+$ cholesterol and ApoE4 $(20 \mathrm{nM})+$ cholesterol for 4 and $24 \mathrm{~h}$. After the treatment the media was collected and BDNF levels were measured by immunoblot.

At $4 \mathrm{~h}$ the amount of secreted m-BDNF $(14 \mathrm{kDa})$ was increased by 22.5-times in ApoE2 + cholesterol treated cells and 1.52-times in ApoE3 + cholesterol treated cells compared to only cholesterol treated cells. (ANOVA: $\mathrm{F}_{(3,8)}=269.3 ; P<0.0001$ ) (Fig. 2a, b). After $24 \mathrm{~h}$, secreted $\mathrm{m}$-BDNF was increased by 143.5 fold in ApoE2 + cholesterol treated cells and 38.4 -fold in ApoE3 + cholesterol treated cells compared to only cholesterol treated cells (ANOVA: $\mathrm{F}_{(3,8)}=151.3$; $P<0.0001$ ) (Fig. 2d, e). ApoE4 + cholesterol treated cells showed no change in secreted $\mathrm{m}-\mathrm{BDNF}$ at 4 and $24 \mathrm{~h}$. 


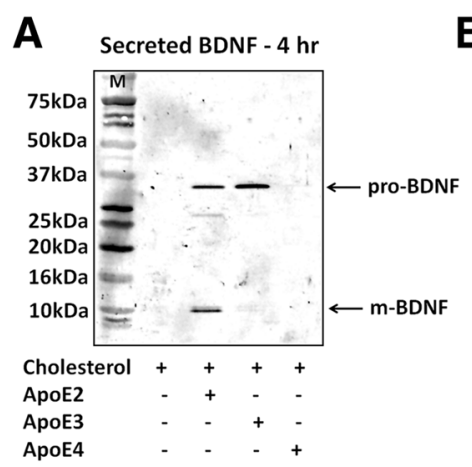

B Secreted mature-BDNF
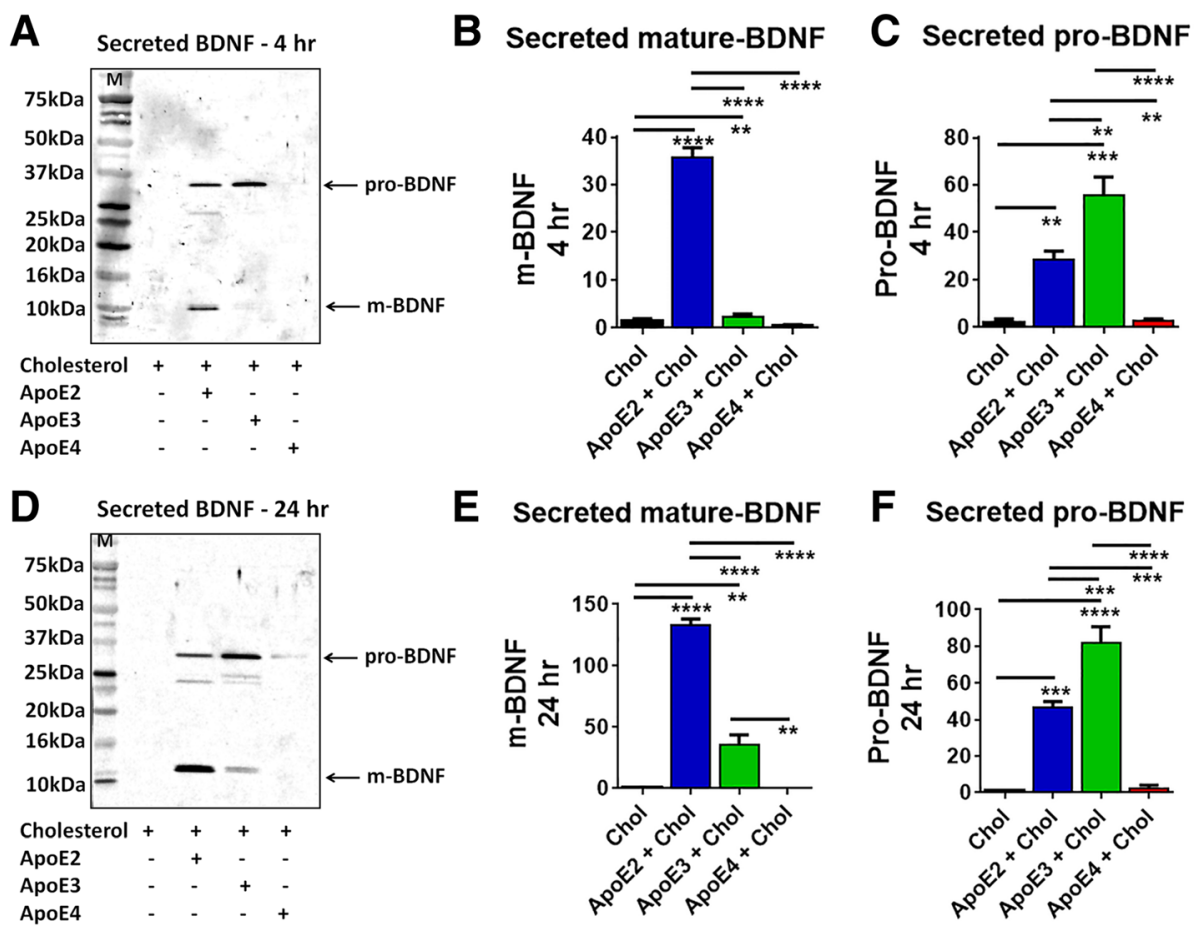

Fig. 2 ApoE isoforms differentially regulate the secretion of mature-BDNF. Primary human astrocytes were treated with cholesterol (Chol; $100 \mu \mathrm{M})$, with or without ApoE2 (20 nM) or ApoE3 (20 nM) or ApoE4 (20 nM) for 4 and $24 \mathrm{~h}$. a and $\mathbf{d}$ Immunoblot showing expression levels of BDNF in the astrocyte-secreted media after 4 and $24 \mathrm{~h}$ respectively. ' $M$ ' indicates molecular weight marker. $\mathbf{b}$ and $\mathbf{e}$ ApoE2 + cholesterol induce the secretion of $\mathrm{m}$ BDNF. $\mathbf{c}$ and $\mathbf{f}$ Expression levels of secreted pro-BDNF in different ApoE isoforms treated cells. Data are represented as mean \pm SE of three independent experiments. $\left({ }^{*} P<0.05,{ }^{* *} P<0.005{ }^{* * *} P<0.0005\right.$ and ${ }^{* * *} P<0.00005$; ANOVA, post hoc Newman-Keuls multiple comparison)

Secreted pro-BDNF level was increased by 13.8 - fold in ApoE2 + cholesterol treated cells and 30 -fold in ApoE3 + cholesterol treated cells compared to cholesterolonly treated cells (ANOVA: $\mathrm{F}_{(3,8)}=32.0 ; P<0.0001$ ) after $4 \mathrm{~h}$ (Fig. 2a, c). At $24 \mathrm{~h}$, secreted pro-BDNF levels increased by 48.7 -fold in ApoE2 + cholesterol treated cells and by 85.4-fold in ApoE3 + cholesterol treated cells compared to cholesterol-only treated cells (ANOVA: $F_{(3,8)}=62.7$; $P<0.0001$ ) (Fig. 2d, f). ApoE4 + cholesterol treated cells showed no significant change in secreted pro-BDNF at 4 and $24 \mathrm{~h}$ (Fig. 2a, d). No prepro-BDNF was detected in the extracellular media.

\section{ApoE2 increased, while ApoE4 decreased the expression of intracellular prepro-BDNF in astrocytes}

We have shown earlier that ApoE4 suppress the expression of BDNF mRNA [9]. To determine if the ApoE isoforms differentially regulate the intracellular protein expression of BDNF, we measured the intracellular protein levels of BDNF from human astrocytes treated with cholesterol, ApoE2 + cholesterol, ApoE2 + cholesterol and ApoE $4+$ cholesterol for 4 and $24 \mathrm{~h}$. At $4 \mathrm{~h}$ the amount of intracellular prepro-BDNF showed no significant difference in cells treated with different ApoE isoforms. After $24 \mathrm{~h}$, the ApoE2 + cholesterol treated cells showed a $19.04 \pm 6.68 \%$ increase, ApoE3 + cholesterol treated cells showed no significant change while ApoE4 + cholesterol treated cells showed a $21.61 \pm 5.89 \%$ decrease in intracellular prepro-BDNF (ANOVA: $\mathrm{F}$ $(3,8)=23.2 ; P=0.0003$ ) (Fig. 3a, b). Mature-BDNF and pro-BDNF were not detected in these fractions.

\section{Discussion}

Brain-derived neurotrophic factor (BDNF) is involved in multiple aspects of synaptogenesis, from the formation to the functional maturation of synapses. BDNF influences the morphological complexity of axons and dendrites [15-17], increases synapse number [18-20], modulate synaptic maturation and controls ultrastructural composition of synapses $[21,22]$. BDNF is critical for synaptic plasticity and memory processing in adult brain and is also essential to promote short and long term memory [23-26]. BDNF is synthesized as a precursor (pro-BDNF) encompassing two domains, the prodomain and the mature BDNF domain [27]. The pro-BDNF is cleaved by prohormone convertases such as furin and $\mathrm{PC} 1 / 3$ intracellularly or plasminogen/plasmin and MMPs extracellularly [28-30] to release the mature form [31].

Our data show that ApoE2 induces the astrocytes to secrete more m-BDNF than does ApoE3, while ApoE4 

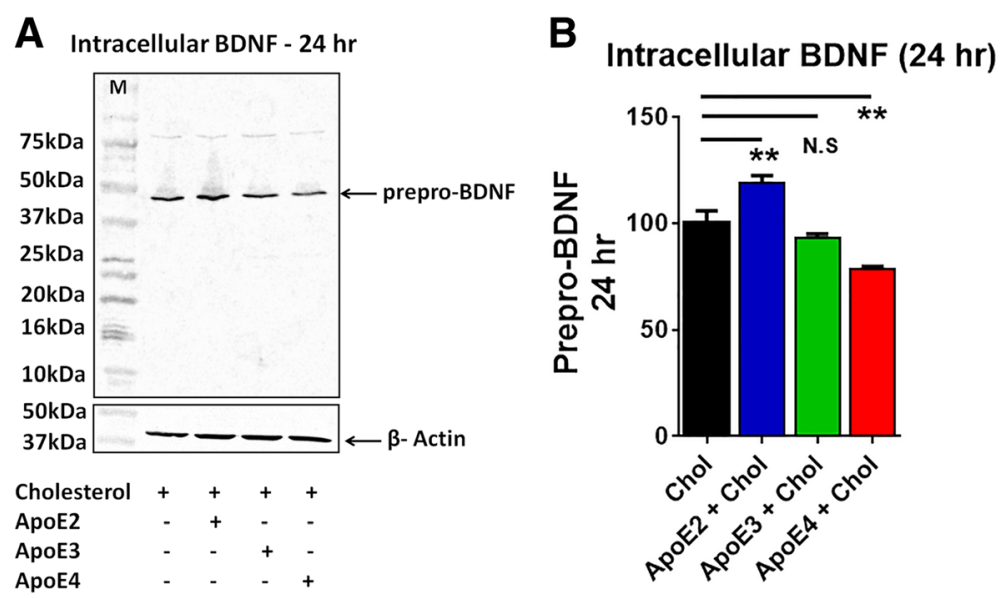

Fig. 3 ApoE4 inhibits the expression of intracellular prepro-BDNF. Primary human astrocytes were treated with cholesterol (Chol; $100 \mu \mathrm{M})$, with or without ApoE2 (20 nM) or ApoE3 (20 nM) or ApoE4 (20 nM) for 24 h. a Immunoblot showing expression levels of BDNF in the cell lysate after 24 h. 'M' indicates molecular weight marker. b ApoE2 + cholesterol induces while ApoE4 + cholesterol inhibits BDNF synthesis. Data are represented as mean \pm SE of three independent experiments $\left({ }^{*} p<.05 ;{ }^{* *} p<.05 ;{ }^{* * *} p<.005\right.$; one-way ANOVA, post hoc Newman-Keuls multiple comparison test)

produces a negligible amount. We also found that the secreted pro-BDNF level was higher in ApoE3-treated astrocytes than in ApoE2-treated astrocytes. Our findings thus suggest that ApoE2 is critically involved in cleavage of pro-BDNF to $\mathrm{m}$-BDNF. The $\mathrm{m}$-BDNF binds to Trk-B receptors leading to cell survival and differentiation, whereas pro-BDNF binds to $75^{\mathrm{NTR}}$ leading to apoptosis [32]. Infusion of exogenous pro-BDNF promotes synapse elimination, whereas $\mathrm{m}-\mathrm{BDNF}$ infusion substantially delays synapse elimination [33]. Exogenous $\mathrm{m}$-BDNF induces LTP and promotes long-term memory (LTM). ApoE4-transgenic mice have impaired long-term spatial memory with reduced dendritic spine density compared to ApoE3 or ApoE2 mice [34]. Persistent LTMs are associated with increased BDNF protein levels [26, 35]. Here we found that the total intracellular BDNF protein is lower in ApoE4-treated cells, higher in ApoE2-treated cells and remains unchanged in ApoE3-treated cells. We have demonstrated earlier, that ApoE3 induces and ApoE4 suppresses BDNF transcription, epigenetically by inducing nuclear translocation and association of HDAC6 to BDNF promoter IV [9]. Thus, ApoE4 is not only blocking the secretion and conversion of pro-BDNF to m-BDNF, but also preventing its synthesis via HDAC. Together our data indicate that ApoE regulates BDNF transcription, maturation and secretion in an isoform dependent manner. ApoE2 and ApoE3 may induce transcription, while ApoE4 inhibits transcription of BDNF via LRP1-HDAC pathway [9]. ApoE2 has very low binding affinity to LDLR (1-2\% that of ApoE3; [36, 37]) and lower affinity than ApoE3 for LRP1 (40\% of ApoE3 or ApoE4; [38, 39]). ApoE induces maturation and secretion of $\mathrm{m}-\mathrm{BDNF}$ in an ApoE2 > ApoE3 > ApoE4 rank order. The differential maturation and secretion of BDNF could be regulated by the pro-BDNF cleaving enzymes viz. furin and plasmin in an ApoE-isoform dependent manner [40]. These findings correlate with the previous findings that BDNF expression and maturation is impaired by ApoE4 which may play an important role in the ApoE4 mediated deficit in long-term memory.

ApoE4, the greatest genetic risk factor for sporadic Alzheimer's disease (AD), increases risk $\sim 3$ - and 15-fold with a single or double allele $[2,41,42]$ compared to ApoE3, whereas ApoE2 decreases AD risk 2-fold per allele [43]. In EFAD transgenic mice generated by crossing $5 x F A D$ mice and $\mathrm{h}-A P O E-\mathrm{TR}$ mice BDNF levels are decreased in the following pattern: E2FAD > E3FAD > 5xFAD/APOE$\mathrm{KO}>\mathrm{E} 4 \mathrm{FAD}$ [44]. We found that BDNF protein levels are lower in human $\mathrm{AD}$ hippocampus, confirming the previous report that precursor form of BDNF and $\mathrm{m}-\mathrm{BDNF}$ are decreased in the pre-clinical stages of Alzheimer's disease [12].

Considering the common role of ApoE and BDNF in synaptogenesis, neuroprotection, synaptic plasticity and learning and memory, our results indicate a mechanistic link between ApoE isoforms and BDNF in maintaining synaptic plasticity. ApoE4 impairs the synthesis and secretion of BDNF which may cause synaptic loss and neuronal integrity $[45,46]$, reduced exitatory synaptic transmission and dendritic arborization [47] and loss of cognition and memory [44, 48, 49], leading to increased risk of AD. ApoE2 and ApoE3 induce BDNF expression and secretion and further downstream signaling pathways which may prevent the synaptic loss in AD [50]. ApoE2 overexpression ameliorates spine density loss in both $\operatorname{Tg} 2576$ and PDAPP mice [51]. ApoE3, but not ApoE4, protectected against neuronal damage in agedependent neurodegeneration [52] and $A \beta$-oligomer- 
mediated synaptic loss through PKCe [8]. PKC $\varepsilon$ is another synaptogenic factor which shows a deficit in human AD hippocampus [53] and humanized ApoE4 transgenic mice [8]. PKC $\varepsilon$ activators (bryostatin 1, DCP-LA) have been shown to induce synaptogenesis [54] and prevent synaptic loss in aged and AD mice by inducing BDNF expression [55-57].

\section{Conclusion}

The findings presented here, taken together, shows that ApoE isoforms differentially regulate BDNF expression and secretion and therefore, provide additional mechanistic insight as to how ApoE2 and ApoE3 may offer neuroprotection through BDNF, and how ApoE4 may cause neurodegeneration by inhibiting BDNF. It will be of future interest to clinically test how such defects in BDNF and neurodegeneration may be prevented by therapeutic use of PKC $\varepsilon$ activators [58].

\section{Abbreviations}

AD: Alzheimer's disease; ApoE: Apolipoprotein E; BDNF: Brain derived neurotrophic factor

\section{Acknowledgements}

Not applicable.

\section{Funding}

This study was funded by Blanchette Rockefeller Neurosciences Institute's internal grant.

\section{Availability of data and materials}

Not applicable.

\section{Authors' contributions}

AS conceived the study, performed all the experiments, did statistical analysis, and helped with data interpretation and drafting the manuscript. TJN was responsible for critical analysis of the data and writing the manuscript. DLA provided the brain samples and helped in writing the manuscript. All authors read and approved the final manuscript.

\section{Competing interests}

The authors declare that they have no competing interests.

\section{Consent for publication}

All authors critically revised the manuscript and approved the final version before submission.

\section{Ethics approval and consent to participate}

Fresh frozen human brain tissue was obtained from the Harvard Brain Tissue Resource Center, McLean Hospital, Boston, MA which is the part of $\mathrm{NIH}$ NeuroBioBank (IRB: Partners Human Research Committee; Title: Brain Tissue Repository for Research on Neurological and Psychiatric Disorders; IRB No: 2015P002028) (Table. 1). Approval for the study was obtained from tissue access committee of NIH NeuroBioBank (https://neurobiobank.nih.gov/ documents/). Informed consent was obtained from all patients or legal representatives.

Received: 17 May 2017 Accepted: 25 May 2017

Published online: 01 June 2017

\section{References}

1. Farrer LA, Cupples LA, Haines JL, Hyman B, Kukull WA, Mayeux R, et al. Effects of age, sex, and ethnicity on the association between apolipoprotein E genotype and Alzheimer disease. A meta-analysis. APOE and Alzheimer disease meta analysis consortium. JAMA. 1997;278:1349-56.
2. Liu CC, Kanekiyo T, Xu H, Bu G. Apolipoprotein E and Alzheimer disease: risk, mechanisms and therapy. Nat rev Neurol. 2013;9:106-18.

3. Mayeux R, Ottman R, Maestre G, Ngai C, Tang MX, Ginsberg H, et al. Synergistic effects of traumatic head injury and apolipoprotein-epsilon 4 in patients with Alzheimer's disease. Neurology. 1995;45:555-7.

4. Yang CP, Gilley JA, Zhang G, Kernie SG. ApoE is required for maintenance of the dentate gyrus neural progenitor pool. Development. 2011;138:4351-62.

5. Buttini M, Yu GQ, Shockley K, Huang Y, Jones B, Masliah E, et al. Modulation of Alzheimer-like synaptic and cholinergic deficits in transgenic mice by human apolipoprotein $\mathrm{E}$ depends on isoform, aging, and overexpression of amyloid beta peptides but not on plaque formation. J Neurosci. 2002;22:10539-48.

6. Klein RC, Mace BE, Moore SD, Sullivan PM. Progressive loss of synaptic integrity in human apolipoprotein E4 targeted replacement mice and attenuation by apolipoprotein E2. Neuroscience. 2010;171:1265-72.

7. Verghese PB, Castellano JM, Holtzman DM. Apolipoprotein E in Alzheimer's disease and other neurological disorders. Lancet Neurol. 2011;10:241-52.

8. Sen A, Alkon DL, Nelson TJ. Apolipoprotein E3 (ApoE3) but not ApoE4 protects against synaptic loss through increased expression of protein kinase C epsilon. J Biol Chem. 2012;287:15947-58.

9. Sen A, Nelson TJ, Alkon DL. ApoE4 and Abeta Oligomers reduce BDNF expression via HDAC nuclear translocation. J Neurosci. 2015;35:7538-51.

10. Siegel GJ, Chauhan NB. Neurotrophic factors in Alzheimer's and Parkinson's disease brain. Brain res Brain res rev. 2000;33:199-227.

11. Holsinger RM, Schnarr J, Henry P, Castelo VT, Fahnestock M. Quantitation of BDNF mRNA in human parietal cortex by competitive reverse transcriptionpolymerase chain reaction: decreased levels in Alzheimer's disease. Brain res Mol Brain res. 2000;76:347-54.

12. Peng S, Wuu J, Mufson EJ, Fahnestock M. Precursor form of brain-derived neurotrophic factor and mature brain-derived neurotrophic factor are decreased in the pre-clinical stages of Alzheimer's disease. J Neurochem. 2005;93:1412-21.

13. Dougherty KD, Dreyfus CF, Black IB. Brain-derived neurotrophic factor in astrocytes, oligodendrocytes, and microglia/macrophages after spinal cord injury. Neurobiol Dis. 2000;7:574-85.

14. Sweet RA, MacDonald ML, Kirkwood CM, Ding Y, Schempf T, JonesLaughner J, et al. Apolipoprotein $\mathrm{E}^{*} 4\left(\mathrm{APOE}^{*} 4\right)$ genotype is associated with altered levels of glutamate signaling proteins and synaptic Coexpression networks in the prefrontal cortex in mild to moderate Alzheimer disease. Mol Cell Proteomics. 2016;15:2252-62.

15. Cohen-Cory S, Kidane AH, Shirkey NJ, Marshak S. Brain-derived neurotrophic factor and the development of structural neuronal connectivity. Dev Neurobiol. 2010;70:271-88.

16. Lom B, Cohen-Cory S. Brain-derived neurotrophic factor differentially regulates retinal ganglion cell dendritic and axonal arborization in vivo. J Neurosci. 1999; 19:9928-38.

17. Cohen-Cory S, Fraser SE. Effects of brain-derived neurotrophic factor on optic axon branching and remodelling in vivo. Nature. 1995;378:192-6.

18. Alsina B, Vu T, Cohen-Cory S. Visualizing synapse formation in arborizing optic axons in vivo: dynamics and modulation by BDNF. Nat Neurosci. 2001; 4:1093-101.

19. Sanchez AL, Matthews BJ, Meynard MM, Hu B, Javed S, Cohen Cory S. BDNF increases synapse density in dendrites of developing tectal neurons in vivo. Development. 2006;133:2477-86.

20. Aguado F, Carmona MA, Pozas E, Aguilo A, Martinez-Guijarro FJ, Alcantara S, et al. BDNF regulates spontaneous correlated activity at early developmental stages by increasing synaptogenesis and expression of the $\mathrm{K}+/ \mathrm{Cl}$ - co-transporter KCC2. Development. 2003;130:1267-80.

21. Kellner Y, Godecke N, Dierkes T, Thieme N, Zagrebelsky M, Korte M. The BDNF effects on dendritic spines of mature hippocampal neurons depend on neuronal activity. Front Synaptic Neurosci. 2014;6:5.

22. Collin C, Vicario-Abejon C, Rubio ME, Wenthold RJ, McKay RD, Segal M. Neurotrophins act at presynaptic terminals to activate synapses among cultured hippocampal neurons. Eur J Neurosci. 2001;13:1273-82.

23. Alonso M, Vianna MR, Izquierdo I, Medina JH. Signaling mechanisms mediating BDNF modulation of memory formation in vivo in the hippocampus. Cell Mol Neurobiol. 2002;22:663-74.

24. Alonso M, Vianna MR, Depino AM, Mello e Souza T, Pereira P, Szapiro G, et al. BDNF-triggered events in the rat hippocampus are required for both short- and long-term memory formation. Hippocampus. 2002;12:551-60.

25. Yamada K, Nabeshima T. Brain-derived neurotrophic factor/TrkB signaling in memory processes. J Pharmacol Sci. 2003;91:267-70. 
26. Bekinschtein P, Cammarota M, Katche C, Slipczuk L, Rossato Jl, Goldin A, et al. BDNF is essential to promote persistence of long-term memory storage. Proc Natl Acad Sci U S a. 2008;105:2711-6.

27. Seidah NG, Benjannet S, Pareek S, Chretien M, Murphy RA. Cellular processing of the neurotrophin precursors of NT3 and BDNF by the mammalian proprotein convertases. FEBS Lett. 1996;379:247-50.

28. Goodman LJ, Valverde J, Lim F, Geschwind MD, Federoff HJ, Geller Al, et al. Regulated release and polarized localization of brain-derived neurotrophic factor in hippocampal neurons. Mol Cell Neurosci. 1996;7:222-38.

29. MacQueen GM, Ramakrishnan K, Croll SD, Siuciak JA, Yu G, Young LT, et al. Performance of heterozygous brain-derived neurotrophic factor knockout mice on behavioral analogues of anxiety, nociception, and depression. Behav Neurosci. 2001;115:1145-53.

30. Mowla SJ, Farhadi HF, Pareek S, Atwal JK, Morris SJ, Seidah NG, et al. Biosynthesis and post-translational processing of the precursor to brainderived neurotrophic factor. J Biol Chem. 2001;276:12660-6.

31. Matsumoto T, Rauskolb S, Polack M, Klose J, Kolbeck R, Korte M, et al. Biosynthesis and processing of endogenous BDNF: CNS neurons store and secrete BDNF, not pro-BDNF. Nat Neurosci. 2008;11:131-3.

32. Lee R, Kermani P, Teng KK, Hempstead BL. Regulation of cell survival by secreted proneurotrophins. Science. 2001;294:1945-8.

33. Je HS, Yang F, Ji Y, Potluri S, Fu X-Q, Luo Z-G, et al. ProBDNF and mature BDNF as punishment and reward signals for synapse elimination at mouse neuromuscular junctions. J Neurosci. 2013;33:9957-62.

34. Rodriguez GA, Burns MP, Weeber EJ, Rebeck GW. Young APOE4 targeted replacement mice exhibit poor spatial learning and memory, with reduced dendritic spine density in the medial entorhinal cortex. Learn Mem. 2013;20:256-66

35. Bekinschtein P, Cammarota M, Izquierdo I, Medina JH. BDNF and memory formation and storage. Neuroscientist. 2008;14:147-56.

36. Dong LM, Innerarity TL, Arnold KS, Newhouse YM, Weisgraber KH. The carboxyl terminus in apolipoprotein E2 and the seven amino acid repeat in apolipoprotein E-Leiden: role in receptor-binding activity. J Lipid res. 1998; 39:1173-80.

37. Simmons T, Newhouse YM, Arnold KS, Innerarity TL, Weisgraber KH. Human low density lipoprotein receptor fragment. Successful refolding of a functionally active ligand-binding domain produced in Escherichia coli. J Biol Chem. 1997;272: 25531-6.

38. Kowal RC, Herz J, Weisgraber KH, Mahley RW, Brown MS, Goldstein JL. Opposing effects of apolipoproteins $E$ and $C$ on lipoprotein binding to low density lipoprotein receptor-related protein. J Biol Chem. 1990;265:10771-9.

39. Weisgraber KH, Innerarity TL, Mahley RW. Abnormal lipoprotein receptorbinding activity of the human $\mathrm{E}$ apoprotein due to cysteine-arginine interchange at a single site. J Biol Chem. 1982;257:2518-21.

40. Ledesma MD, Abad-Rodriguez J, Galvan C, Biondi E, Navarro P, Delacourte $A$, et al. Raft disorganization leads to reduced plasmin activity in Alzheimer's disease brains. EMBO rep. 2003:4:1190-6.

41. Corder EH. Gene dose of apolipoprotein E type 4 allele and the risk of Alzheimer's disease in late onset families. Science. 1993;261:921-3.

42. Khachaturian AS, Corcoran CD, Mayer LS, Zandi PP, Breitner JC. Apolipoprotein E epsilon4 count affects age at onset of Alzheimer disease, but not lifetime susceptibility: the Cache County study. Arch gen Psychiatry. 2004;61:518-24.

43. Roses AD. Apolipoprotein E alleles as risk factors in Alzheimer's disease. Annu rev med. 1996:47:387-400.

44. Liu DS, Pan XD, Zhang J, Shen H, Collins NC, Cole AM, et al. APOE4 enhances age-dependent decline in cognitive function by down-regulating an NMDA receptor pathway in EFAD-Tg mice. Mol Neurodegener. 2015;10:7.

45. White F, Nicoll JA, Roses AD, Horsburgh K. Impaired neuronal plasticity in transgenic mice expressing human apolipoprotein E4 compared to E3 in a model of entorhinal cortex lesion. Neurobiol Dis. 2001;8:611-25.

46. Cambon K, Davies HA, Stewart MG. Synaptic loss is accompanied by an increase in synaptic area in the dentate gyrus of aged human apolipoprotein E4 transgenic mice. Neuroscience. 2000;97:685-92.

47. Wang C, Wilson WA, Moore SD, Mace BE, Maeda N, Schmechel DE, et al. Human apoE4-targeted replacement mice display synaptic deficits in the absence of neuropathology. Neurobiol Dis. 2005;18:390-8.

48. Bour A, Grootendorst J, Vogel E, Kelche C, Dodart JC, Bales K, et al. Middleaged human apoE4 targeted-replacement mice show retention deficits on a wide range of spatial memory tasks. Behav Brain res. 2008;193:174-82.
49. Grootendorst J, Bour A, Vogel E, Kelche C, Sullivan PM, Dodart JC, et al. Human apoE targeted replacement mouse lines: h-apoE4 and h-apoE3 mice differ on spatial memory performance and avoidance behavior. Behav Brain res. 2005;159:1-14.

50. Nelson TJ, Alkon DL. Molecular regulation of synaptogenesis during associative learning and memory. Brain Res. 2015;1621:239-51.

51. Lanz TA, Carter DB, Merchant KM. Dendritic spine loss in the hippocampus of young PDAPP and Tg2576 mice and its prevention by the ApoE2 genotype. Neurobiol Dis. 2003;13:246-53.

52. Buttini M, Orth M, Bellosta S, Akeefe H, Pitas RE, Wyss-Coray T, et al. Expression of human apolipoprotein E3 or E4 in the brains of Apoe-/- mice: isoform-specific effects on neurodegeneration. J Neurosci. 1999;19:4867-80.

53. Khan TK, Sen A, Hongpaisan J, Lim CS, Nelson TJ, Alkon DL. PKCepsilon deficits in Alzheimer's disease brains and skin fibroblasts. J Alzheimers Dis. 2015:43:491-509.

54. Sen A, Hongpaisan J, Wang D, Nelson TJ, Alkon DL. PKC epsilon promotes Synaptogenesis through membrane accumulation of the postsynaptic density protein PSD-95. J Biol Chem. 2016;291:16462-76.

55. Hongpaisan J, Sun MK, Alkon DL. PKC epsilon activation prevents synaptic loss, Abeta elevation, and cognitive deficits in Alzheimer's disease transgenic mice. J Neurosci. 2011;31:630-43.

56. Hongpaisan J, Xu C, Sen A, Nelson TJ, Alkon DL. PKC activation during training restores mushroom spine synapses and memory in the aged rat. Neurobiol Dis. 2013;55:44-62.

57. Neumann JT, Thompson JW, Raval AP, Cohan CH, Koronowski KB, Perez-Pinzon MA. Increased BDNF protein expression after ischemic or PKC epsilon preconditioning promotes electrophysiologic changes that lead to neuroprotection. J Cereb Blood Flow Metab. 2015;35:121-30.

58. Nelson TJ, Alkon DL. Neuroprotective versus tumorigenic protein kinase C activators. Trends Biochem Sci. 2009:34:136-45.

\section{Submit your next manuscript to BioMed Central and we will help you at every step:}

- We accept pre-submission inquiries

- Our selector tool helps you to find the most relevant journal

- We provide round the clock customer support

- Convenient online submission

- Thorough peer review

- Inclusion in PubMed and all major indexing services

- Maximum visibility for your research

Submit your manuscript at www.biomedcentral.com/submit
Biomed Central 